\title{
Key findings from the second Australian Child and Adolescent Survey of Mental Health and Wellbeing
}

Running title: Prevalence of mental disorders in Australian children and adolescents

David Lawrence ${ }^{1}$, Jennifer Hafekost ${ }^{1}$, Sarah E Johnson ${ }^{1}$, Suzy Saw ${ }^{2}$, William J Buckingham ${ }^{3}$, Michael G Sawyer ${ }^{4}$, John Ainley ${ }^{5}$, Stephen R Zubrick ${ }^{1}$,

1 Telethon Kids Institute, The University of Western Australia, Perth, Australia

$2 \quad$ Health Data Analysis Pty Ltd

3 Buckingham \& Associates Pty Ltd

4 Discipline of Paediatrics, University of Adelaide, Adelaide, Australia

5 Australian Council for Educational Research, Melbourne, Australia

\section{Corresponding Author:}

David Lawrence, Telethon Kids Institute, The University of Western Australia, PO Box 855, West Perth WA 6872, Australia. Tel: +61 89489 7720, Fax: +61 894897700

Email: David.Lawrence@telethonkids.org.au

Word count: 4,619 


\section{Abstract}

Objective: To estimate the prevalence of mental disorders in children and adolescents in Australia, and the severity and impact of those mental disorders.

Method: Seven mental disorders were assessed using the parent or carer completed version of the Diagnostic Interview Schedule for Children Version IV (DISC-IV), and major depressive disorder was also assessed using the youth self-report version of the DISC-IV. Severity and impact were assessed using an extended version of the DISC-IV impact on functioning questions, and days absent from school due to symptoms of mental disorders. Data were collected in a national face-to-face survey of 6,310 parents or carers of children and adolescents aged 4-17 years, with 2,969 young people aged $11-17$ years also completing a self-report questionnaire.

Results: 12 -month prevalence of mental disorders was $13.9 \%$, with $2.1 \%$ of children and adolescents having severe disorders, 3.5\% having moderate disorders and $8.3 \%$ having mild disorders. The most common class of disorders was ADHD followed by anxiety disorders. Mental disorders were more common in step-, blended- or one parent families, in families living in rented accommodation and families where one or 
both carers were not in employment. Mental disorders were associated with a substantial number of days absent from school particularly in adolescents.

Conclusions: Mental disorders are common in children and adolescents, often have significant impact, and are associated with substantial absences from school. Child and adolescent mental disorders remain an important public health problem in Australia. Accurate information about prevalence and severity of child and adolescent mental disorders is an essential prerequisite for effective mental health policy and service planning.

Key words: mental disorders, prevalence, epidemiology, DSM-IV. 


\section{Introduction}

Mental disorders are one of the most common chronic health conditions of young people (Erskine et al., 2014). As well as causing significant disability and burden they can impact a child's life prospects if learning and development are impeded (Patel et al., 2007; Patton et al., 2014).

Epidemiological surveys of adults under the banner of the World Mental Health Survey Initiative have been conducted in 28 countries to date (Kessler et al., 2008) including in Australia in 1997 and 2007, demonstrating the focus that has been placed on adult mental health. These surveys have also shown that a high proportion of adults with mental illness have first onset of symptoms in childhood or adolescence (Kessler et al., 2005; Slade et al., 2009). This is particularly so for anxiety disorders, psychoses and substance dependence disorders. Despite this, surprisingly few countries have conducted national surveys of mental disorders in children and young people. The first Australian Child and Adolescent Survey of Mental Health and Wellbeing, conducted in 1998, was the first national survey anywhere in the world that assessed child and adolescent mental disorders according to diagnostic criteria (Sawyer et al., 2000). Since that time, the British Child and Adolescent Mental Health Survey has been conducted 
twice (Ford et al., 2003; Green et al., 2005), and mental disorders were assessed in adolescents in the United States in the National Health and Nutrition Examination Survey from 2001-2004 (Merikangas et al., 2010), and in the National Comorbidity Survey Replication Adolescent Supplement conducted in 2004 (Kessler et al., 2012). Despite the high proportion of adult mental disorders with first onset in childhood or adolescence, and their importance in life course outcomes, much less is known about the epidemiology of child and adolescent mental disorders (Merikangas et al., 2009).

Results from the 1998 Australian child and adolescent survey provided a foundation for reforms to mental health services for children and young people (Sawyer et al., 2001). Since 1998, there have been major changes in services available for children and young people and their families. These include the introduction of the Better Access program which provides, among other things, additional Medicare funding for psychological services; the national roll-out of youth mental health services specifically for young people under 25 years through headspace; and the KidsMatter and MindMatters mental health literacy programs for schools. Since 1998 most Australian jurisdictions have implemented new mental health policies and plans, and reviewed or reconfigured their child and adolescent mental health services. Many schools and school jurisdictions within the public, Catholic and independent sectors have 
developed general student wellbeing programs as well as recognising the need for individual help and support by student counsellors and mental health professionals where necessary. These initiatives, flowing from the first national survey, invite a strategic opportunity to epidemiologically assess their reach, uptake and impact along with reassessing the current prevalence and impact of mental disorders in young people. Up to date information about prevalence and severity of child and adolescent mental disorders is an essential prerequisite for effective mental health policy and planning.

Re-assessment of the prevalence of child and adolescent mental disorders and their impact has to take into account the significant social changes that have occurred in Australia since the time of the first national survey. For example, new technologies including widespread use of social media have changed the nature and exposure to bullying (e.g. cyber-bullying) (Bor et al., 2014). Structural changes in the labour market, with a higher proportion of jobs requiring advanced education and higher proportions of adolescents participating in post-school education, have the potential to impact upon the level of stress adolescents feel to perform academically (Larson et al., 2002; West et al. 2003). 
There are effective treatments for many child and adolescent mental health conditions (US Department of Health and Human Services, 1999). However, previous studies have shown that relatively few children and adolescents with problems access these treatments in a timely fashion (Merikangas et al., 2009; Sawyer et al. 2001). As such, these young people miss out on treatment benefits such as shorter illness duration, reduced illness severity and long term disability (US Department of Health and Human Services, 1999).

The second Australian Child and Adolescent Survey of Mental Health and Wellbeing, provides updated prevalence estimates of the most common and impactful mental disorders. The survey specifically captured the changes in services and how these are delivered since the first national survey in 1998. This paper describes:

1. the prevalence and severity of mental disorders in children and adolescents using standardised instruments applying diagnostic criteria; and 2. factors associated with the prevalence of these disorders. 


\section{Materials and methods}

Data source

A national survey of the parents and carers of 6,310 children and adolescents aged 417 years was undertaken. Face-to-face interviews were conducted with the primary carer of the selected child in each household, and if the selected child was aged 11-17 years, these young people were asked to complete a self-report questionnaire in private on a tablet computer. Language translation facilities were not available for the survey, and if the primary carer or selected survey child did not speak English the survey interview did not proceed. The response rate to the household survey was $55 \%$, and $89 \%$ of eligible adolescents in these households completed the self-report questionnaire. The design of the survey has been described in detail elsewhere (Hafekost et al., submitted). Participation in the survey was voluntary and all participants gave written consent to participate in it. The research protocol for the study was approved by the Australian Government Department of Health Human Research Ethics Committee, and The University of Western Australia Human Research Ethics Committee. 
Measures

Mental disorders: Mental disorders were assessed using the Diagnostic Interview Schedule for Children Version IV (DISC-IV) (Fisher et al., 1993; Shaffer et al., 2000). Seven disorder modules were selected for the survey to be administered to primary carers-social phobia, separation anxiety disorder, generalised anxiety disorder, obsessive-compulsive disorder, major depressive disorder, attentiondeficit/hyperactivity disorder (ADHD) and conduct disorder. These were selected based on the prevalence and impact of these conditions. The youth self-report version of the major depressive disorder module was also included in the youth self-report questionnaire (Hafekost et al., submitted). The DISC-IV implements DSM-IV diagnostic criteria for the presence of a mental disorder (American Psychiatric Association, 2000). The DSM-IV specifies that to meet criteria for a mental disorder there must be clear evidence of clinically significant impairment in social, academic, or occupational functioning (i.e. functional domains). The DISC-IV offers four different algorithms for assessing impairment. In line with other national surveys that have used the DISC-IV, including the first Australian child and adolescent survey (Sawyer et al., 2001) and the United States National Health and Nutrition Examination Survey (Merikangas et al., 2010), algorithm $D$ has been used in the present survey. This algorithm requires either 
severe impairment in one or more functional domains or at least moderate impairment in two or more domains. The DISC-IV provides indicators of 12-month prevalence and 30-day prevalence. For ADHD, a minimum symptom duration of six months is required to meet DSM-IV criteria (American Psychiatric Association, 2000). For conduct disorder, the DISC-IV assesses behaviours in the last six months and in the last 12 months prior to the survey. The ratio of 30-day prevalence to 12-month prevalence can be used as a measure of persistence of disorder (Kessler et al., 2012).

Principal condition: If a child or adolescent had symptoms of multiple mental disorders, the primary carer was asked which condition bothered or upset the child or adolescent the most. For children and adolescents who met diagnostic criteria for more than one disorder, this was used to identify a principal condition for each child or adolescent.

Severity: As there is no existing parent or carer reported measure of severity of mental disorders in children and adolescents that can be included in population surveys, a set of items was developed specifically to assess severity of disorder. These items expand on those used for the assessment of impairment in the DISC-IV (Shaffer et al., 2000), and they incorporate concepts used in the Brief Impairment Scale (Bird et al., 2005). The items were designed to assess severity of the mental disorder in four functional 
domains: at school or work, with friends, impact on family and impact on self including personal distress. Severity was rated as either mild, moderate or severe based on ratios consistent with those used in the ongoing work to develop a National Mental Health Services Planning Framework (G Stewart, 2014, personal communication). For the purposes of assessing severity, disorders were grouped into three broad classes. The four anxiety disorders and major depressive disorder were combined into one class, and ADHD and conduct disorder were each treated as separate classes. If parents or carers endorsed sufficient symptoms to generate a DISC-IV diagnosis of more than one disorder within the anxiety/depression class, the severity items were asked only once, in relation to all symptoms. The severity items were asked separately if ADHD or conduct disorder was identified. Questions on days absent from school in the past 12 months due to mental disorders were asked separately for each of the disorder classes.

Sociodemographic factors: Several sociodemographic factors were included in the survey, with correspondence with Australian Bureau of Statistics (ABS) standards as far as possible. Factors considered included family type (based on the ABS definition for family blending, although the ABS uses the label "intact" families which are referred to here as original families), country of birth (Australia or overseas), main language 
spoken (English or another language), socio-economic status, household income, parental education, labour force status, housing tenure and remoteness area. In approximately $4 \%$ of families the primary carer either did not know or would not provide the household income. Socio-economic status was taken from the 2011 ABS Index of Relative Socio-Economic Disadvantage (IRSED) for the Statistical Area 1 (SA1) in which the family was living at the time of the survey (Australian Bureau of Statistics, 2013). Remoteness areas were assigned based on the SA1 of residence at the time of the survey using the ABS Remoteness Areas from the 2011 Census of Population and Housing. The survey excluded the $1 \%$ most remote SA1s from the sampling frame and has poor coverage of very remote areas. As a consequence Remote and Very Remote Australia have been combined.

\section{Statistical analysis}

Survey data have been weighted to represent the full Australian population of 4-17 year-olds, and to adjust for patterns in non-response. In particular, families with children 7 years or under or with more than one child aged 4-17 years were found to be more likely to participate in the survey. Additionally 16-17 year-olds were specifically oversampled. The weighting accounts for these factors. Survey estimates 
and associated confidence intervals have been calculated using the method of Taylor Series Linearisation (Wolter, 2007).

Logistic regression was used to examine the relationship between sociodemographic variables and prevalence of mental disorders. Two sets of regression models were fitted. The first set of univariate models looked at the relationship between each sociodemographic factor and disorder prevalence independently including only age group and sex in the model. A single multivariate model was then produced in which factors that were not independently significantly associated with disorder prevalence were eliminated from the model in order to produce the most parsimonious model. Logistic regression analyses were undertaken using the SAS SURVEYLOGISTIC procedure to account for the clustered nature of the sample design and the use of survey weights. All analyses were conducted using SAS software (SAS Institute Inc, 2014). 


\section{Results}

Prevalence of disorder - parent or carer reported

The parent or carer reported version of the Diagnostic Interview Schedule for Children Version IV (DISC-IV) was employed as the primary measure of mental disorders in children and adolescents. Using this measure, the combined 12-month prevalence of the seven disorders assessed in this survey was $13.9 \%$ (95\% confidence interval $(\mathrm{Cl})=12.9-15.0 \%)$, and the 30-day prevalence was 9.3\% (95\% $\mathrm{Cl}=8.5-10.2 \%)$. ADHD was the most common disorder, with a 12-month prevalence of $7.4 \%(95 \% \mathrm{Cl}=6.6-8.2 \%)$, followed by anxiety disorders as a group at $6.9 \%(95 \% \mathrm{Cl}=6.2-7.6 \%)$ (Table 1$)$.

Among 12 -month cases, $67 \%$ also met diagnostic criteria on the past 30 days. Persistence as measured by ratio of 30-day prevalence to 12-month prevalence (Kessler et al., 2012) was highest for conduct disorder (100\%) and ADHD (80\%), although diagnostic criteria for ADHD require persistence of symptoms for at least six months, and 30-day prevalence for conduct disorder is based on occurrence of behaviours in the past six months. Among 12 -month anxiety disorder cases, $49 \%$ met diagnostic criteria in the past 30 days, as did $24 \%$ of major depressive disorder cases. 
Overall, prevalence of mental disorders was higher in males than females, particularly the prevalence of ADHD (Table 2). Prevalence of ADHD was lower in females 12-17 years than females aged $4-11$ years ( $2.7 \%$ compared with $5.4 \%)$ but about the same for males (9.8\% compared with $10.9 \%)$. Prevalence of separation anxiety disorder was lower for older children, while prevalence of major depressive disorder and social phobia was higher in adolescents (Table 2).

Comorbidity and principal condition

The four main classes of mental disorders assessed in the study often occur together. Some $4.1 \%$ of $4-17$ year-olds had more than one class of mental disorder. This represents $30.1 \%$ of children and adolescents with a mental disorder. Of children and adolescents with disorders, $23.3 \%$ had two classes of disorder, and $6.8 \%$ had three or four classes of disorder. When considering principal condition (the child or adolescent's disorder if they had only one disorder, and the disorder that bothered or upset the child the most for children and adolescents who had more than one disorder), $5.5 \%$ of $4-17$ year-olds had ADHD as their principal condition, $5.4 \%$ had an anxiety disorder, $2.0 \%$ had major depressive disorder, and $1.1 \%$ had conduct disorder (Table 1). 
Youth reported major depressive disorder

Among 11-15 year-old males the prevalence of major depressive disorder based on information reported by young people was similar to that reported by parents and carers, but in females aged 11-15 years and in 16-17 year-olds, the prevalence was substantially higher when based on the youth reported information. When comparing parent and carer identified cases and youth identified cases the degree of overlap was modest (Table 3). When any major depressive disorder case identified based on youth reported information was combined with any case of any of the seven disorders assessed using parent or carer report, the overall prevalence of disorder in children and adolescents aged $4-17$ years was $15.9 \%(95 \% \mathrm{Cl}=14.8-17.0 \%)$.

Demographic characteristics

In addition to sex and age group, the association of nine other socio-demographic characteristics with prevalence of mental disorder was assessed using univariate and multivariate models. In terms of univariate associations, all nine socio-demographic 
characteristics were significantly associated with prevalence of disorder (Table 4). Child and adolescent mental disorders were more prevalent in step, blended or sole parent families compared with original two parent families, were less prevalent if one or both carers was born overseas, or if one or both carers main language was a language other than English. Mental disorders were also more prevalent in families with lower household income, living in areas in the lower quintiles of the index of relative socioeconomic disadvantage, in families where the highest level of educational attainment of either parent or carer was year 10 or below, where both carers or the sole carer were not in employment, and where the family was living in rented accommodation. In terms of remoteness, a higher prevalence of disorder was observed in families living in outer regional Australia (Table 4).

In multivariate logistic regression, sex, family type, country of birth, main language spoken, parent or carer employment status and housing tenure were each found to be independently associated with the prevalence of disorder.

Further analyses by sex and for individual classes of disorder (not shown) found that the association between sociodemographic variables and prevalence of disorder was very similar for both males and females, and broadly similar patterns were seen for 
each disorder group. For ADHD an association was also found with household income in the fully adjusted model, with the odds of a child or adolescent having a diagnosis of ADHD being 1.5 times higher $(95 \% \mathrm{Cl}=1.1-2.3)$ in families in the lowest tercile compared with those in the highest tercile of household income. The results for anxiety disorders closely matched the results for all disorders. In contrast to the model for any disorder, for major depressive disorder (as reported by parents and carers), no association was found between prevalence of depression and main language spoken by the parents or carers. For conduct disorder, an additional association was found with the index of relative socio-economic disadvantage, with children and adolescents living in SA1s in the lowest quintile having 2.3 times higher odds $(95 \% \mathrm{Cl}=1.1-4.7)$ of having conduct disorder than those in the highest quintile. Additionally a stronger association was found with housing tenure, with the odds of having conduct disorder being 7.2 times higher $(95 \% \mathrm{Cl}=2.0-26.4)$ in families in rented public housing compared with those who own their own home outright and 3.9 times higher ( $95 \% \mathrm{Cl}=1.2-12.7)$ in families living in other rented housing. 
Each mental disorder case was rated as either mild, moderate or severe. Overall 8.3\% of 4-17 year-olds had mild disorders in the past 12 months, $3.5 \%$ had moderate disorders and $2.1 \%$ had severe disorders (Table 5). Major depressive disorder was the disorder with the highest proportion of severe cases (42\%), while ADHD had the lowest proportion of severe cases (10\%). The severity measure was derived using an item response theory model (Zubrick et al., 2015c). As a sensitivity analysis, a conceptual mapping of the same items was developed to CGAS ratings. This approach identified an almost identical proportion of mild, moderate and severe cases when defined as CGAS scores 0-40 representing severe cases, $41-50$ representing moderate cases, and 51-60 representing mild cases.

Mental disorders were also associated with substantial days absent from school due to disorder symptoms, particularly for adolescents. Adolescents aged 12-17 years with anxiety disorders had a median 9 days off school due to symptoms of their disorder in the past 12 months (IQR=0-21 days), and adolescents with major depressive disorder had a median 10 days absent from school (IQR=0-28 days) due to symptoms of disorder in the past 12 months. 


\section{Discussion}

Mental disorders are one of the most common conditions affecting children and adolescents, with $13.9 \%$ of $4-17$ year-olds having a mental disorder in the past 12 months. They can have significant impact on children and adolescents and their families, and are associated with substantial absences from school. As mental disorders can adversely affect children's development at critical life stages, they have the potential to change children's trajectories through life. Taken together, the findings of this survey provide a strong justification for continued investment in treatment and prevention of mental disorders in children and young people, and for further prioritising research into the development of mental disorders in childhood and adolescence.

The prevalence of mental disorders varied substantially by sociodemographic characteristics. Of particular note, mental disorders were more common in step, blended or one parent families, in families living in rented accommodation and families where one or both carers were not in employment. Approximately $69 \%$ of $4-17$ yearolds live with both original parents, $20 \%$ live in a sole parent or carer family, and $11 \%$ live in step-, blended or other family types. Some $22.4 \%$ of $4-17$ year-olds living in 
families with a sole parent or carer had a mental disorder in the past 12 months, adding to the burden that these families, some of whom may have less parenting resources, face. The prevalence of mental disorders was highest $(29.3 \%)$ in families with a sole parent or carer who was either unemployed or not in the labour force, highlighting the challenges that these families face. These associations are crosssectional only and causation cannot be implied.

High rates of major depressive disorder were found based on adolescent self-report, particularly so for females and older adolescents. These rates were substantially higher than those based on parent or carer report. The high rates of major depressive disorder based on adolescent self-report were also associated with high rates of reported self-harming and suicidal thoughts and behaviours (Zubrick et al., submitted a; Zubrick et al., submitted b). These findings suggest that parents or carers may not always be aware of the emotional problems that adolescents are experiencing. Avenevoli et al. (2015) reported similarly high levels of major depressive disorder in adolescents aged 13-17 years in the United States. While the prevalence of major depressive disorder may be low in comparison to the prevalence of anxiety disorders and ADHD when considering all children aged 4-17 years, major depressive disorder is a significant contributor to the overall burden of mental disorders in older adolescents. 
The prevalence of mental disorders in Australian children and adolescents is generally comparable with international data. A recent meta-analysis by Polanczyk and colleagues estimated the prevalence of mental disorders in children and adolescents to be $13.5 \%$ based on 41 studies from 27 countries (Polanczyk et al., 2015). The prevalence of anxiety disorders and major depressive disorder in Australia is similar to that reported internationally (Costello et al., 2005, Costello et al., 2006). At 7.4\%, the prevalence of ADHD was higher than the $5.3 \%$ reported in a recent worldwide metaanalysis (Polanczyk et al., 2014). However they noted prevalence rates based on studies using DSM-III-R criteria were on average $2.4 \%$ lower than those based on DSMIV, as used in this study. While ADHD was the most prevalent disorder in this study, the prevalence of ADHD was lower in adolescents compared with children, and it was the disorder with the highest proportion of mild cases.

\section{Limitations and strengths}

There are a number of potential limitations to these results. The DISC applies standard DSM-IV diagnostic criteria, but relies on information provided by parents and carers and young people themselves to determine diagnostic status. The DISC has been 
carefully designed to strictly implement DSM-IV criteria without the need for any judgement on the part of the interviewer. The interviewers were not clinically trained, and it is possible that a clinician might form a different view about a child based on a full clinical appraisal. However, the DISC-IV is a well-validated tool with good concordance with clinical diagnoses (Fisher et al., 1993). Alternative methods for assessing psychiatric morbidity in children and adolescents include the use of short screening scales such as the Strengths and Difficulties Questionnaire (SDQ ) and the Child Behavior Checklist (CBCL), or the use of diagnostic interviews that are supplemented by clinical judgement such as the Child and Adolescent Psychiatric Assessment (CAPA) and the Development and Well-Being Assessment (DAWBA). Because of the time taken to administer questionnaires based on full diagnostic criteria, short screening scales such as the SDQ and the CBCL are commonly used in more general social surveys where only a short amount of interview time can be allotted to each topic. While these scales are well correlated with diagnostic assessment, their overall predictive power of diagnostic status is modest (Krol et al., 2006, Derks et al., 2006). Angold et al. (2012) conducted a study comparing the DISC with the DAWBA and the CAPA. They found comparable results between the DISC and the CAPA, while the DAWBA returned a lower prevalence and identified more severe cases and was more likely to miss milder cases. There is no gold standard for the 
assessment of psychiatric morbidity in children and adolescents, recognising that clinicians vary in their assessment of individual cases and any case assessment is limited by the information available to the practitioner at the time of assessment (Costello, 2015).

Additionally, parents or carers may not always know of their child's mental state, particularly for internalising disorders in older adolescents. If anxiety disorders were included in the youth self-report module this may have identified differences compared with the parent or carer reported prevalences for these disorders.

To manage respondent burden in a lengthy interview, only seven disorders were assessed in the parent or carer interview. The most commonly occurring and impactful conditions were chosen for assessment in the survey. Nonetheless, prevalence may have been higher if other disorders had been considered. For instance, $2.8 \%$ of adolescents aged 13-17 years were assessed as having eating disorders in the United States National Comorbidity Study Replication Adolescent Supplement, 1.6\% had Post traumatic stress disorder and 9.5\% had specific phobias (Kessler et al., 2012). Many young people with eating disorders or PTSD do have comorbidity anxiety, depressive or conduct disorders, and the majority of young people with specific phobias 
experience minimal impact on their overall functioning. As such, the net effect of not covering all possible DSM-IV disorders on overall prevalence is not thought to be large.

Substance use disorders were also not assessed in Young Minds Matter. These are typically very uncommon in children but frequently onset in the later adolescent years. Questions on potentially harmful use of tobacco, alcohol and other drugs were included in the adolescent self-report questionnaire, and prevalence and associations with mental disorders are reported elsewhere (Lawrence et al., 2015). However, restrictions on questionnaire length prevented assessment of the full diagnostic criteria for establishing diagnosis of substance use disorders. In the United States National Comorbidity Survey-Adolescent Supplement, prevalence of substance use disorders was estimated at $8.3 \%$ (Kessler et al., 2012), while $12.1 \%$ of $16-19$ year-olds had substance use disorders in the 2007 Adult National Survey of Mental Health and Wellbeing (Slade et al., 2009). As documented in the 2010 National Drug Strategy Household Survey, use of alcohol, tobacco and other drugs at harmful levels is common in Australian teenagers and adults and have substantial negative impacts on individuals, families and communities (Australian Institute of Health and Welfare, 2011). 
The overall response rate was modest at $55 \%$. Comparison of the survey sample with data from the 2011 Census of Population and Housing found the sample to be representative of the population distribution by socio-economic status, income and employment status of parents or carers, country of birth, main language spoken, and household tenure. The Strengths and Difficulties Questionnaire (SDQ) was administered to parents and carers in the survey, and yielded an overall prevalence of $10.1 \%$ of $4-17$ year-olds in the abnormal range ( $95 \% \mathrm{Cl}=9.2-11.0 \%)$, closely matching the design prevalence of $10 \%$ based on a normative sample of British children and adolescents in the 1990s, suggesting that the rate of emotional or behavioural problems observed in the sample is about what would be expected. Nonetheless it is not possible to know if children and adolescents in families that participated in the survey were more or less likely to have mental disorders than those who did not participate.

The second Australian Child and Adolescent Survey of Mental Health and Wellbeing has provided up to date estimates of the prevalence of mental disorders in children and adolescents, and has expanded on the range of disorders covered in the first survey. Additionally a tool has been developed to assess severity of impact on functioning. This report has described the prevalence, impact and demographic 
correlates of mental disorders in children and adolescents in Australia. Other articles in this issue describe use of services for mental disorders, prevalence of self-harm and suicidal behaviours and associations with mental illness. 


\section{Acknowledgements}

The authors would like to thank the over 6,000 families that gave their time to participate in the survey, Rajni Walia, Gerry Bardsley, and the team at Roy Morgan Research who undertook the data collection, and the Survey Reference Group for their input into the design and conduct of the survey.

Funding

The second Australian Child and Adolescent Survey of Mental Health and Wellbeing was funded by the Australian Government Department of Health.

\section{Declaration of conflicting interests}

The authors declare that there is no conflict of interest. 


\section{References}

American Psychiatric Association (2000) Diagnostic and Statistical Manual of Mental Disorders, Fourth Edition, Text Revision. Washington, DC: American Psychiatric Association.

Angold A, Erkanli A, Copeland W, Goodman R, Fisher PW, Costello EJ (2012) Psychiatric diagnosic interviews for children and adolescents: a comparative study. Journal of the American Academy of Child and Adolescent Psychiatry 51: 506-517.

Australian Bureau of Statistics (2013) Census of Population and Housing: Socioeconomic indicators for areas (SEIFA), Australia, 2011. Canberra: Australian Bureau of Statistics, Cat. 2033.0.55.001.

Australian Institute of Health and Welfare (2011) 2010 National Drug Strategy Household Survey report. Drug statistics series no. 25. Cat. no. PHE 145. Canberra: Australian Institute of Health and Welfare.

Avenevoli S, Swendsen J, He JP, et al. (2015) Major depression in the National Comorbidity Survey-Adolescent Supplement: prevalence, correlates, and treatment. Journal of the American Academy of Child and Adolescent Psychiatry 54: $37-44$. 
Bird HR, Canino GJ, Davies M, et al. (2005) The Brief Impairment Scale (BIS): a multidimensional scale of functional impairment for children and adolescents. Journal of the American Academy of Child and Adolescent Psychiatry 44: 699-707. Bor W, Dean AJ, Najman J, et al. (2014) Are child and adolescent mental health problems increasing in the 21st century? A systematic review. Australian and New Zealand Journal of Psychiatry 87: 606-616.

Costello EJ, Egger HL, Angold A (2005) The developmental epidemiology of anxiety disorders: phenomenology, prevalence, and comorbidity. Child and Adolescent Psychiatric Clinics of North America 14: 631-648.

Costello EJ, Foley DL, Angold A (2006) 10-year research update review: the epidemiology of child and adolescent psychiatric disorders: II. developmental epidemiology. Journal of the American Academy of Child and Adolescent Psychiatry 45: 8-25.

Costello EJ (2015) Commentary: "Diseases of the world": from epidemiology to etiology of child and adolescent pschopathology - a commentary on Polanczyk et al. (2015). Journal of Child Pschology and Psychiatry 56: 366-369.

Derks EM, Hudziak JJ, Dolan CV, et al. (2006) The relations between DISC-IV DSM diagnoses of $\mathrm{ADHD}$ and multi-informant $\mathrm{CBCL}-\mathrm{AP}$ syndrome scores. Comprehensive psychiatry 47: 116-122. 
Erskine HE, Moffitt TE, Copeland WE, et al. (2014) A heavy burden on young minds: the global burden of mental and substance use disorders in children and youth. Psychological Medicine. Epub ahead of print. doi: 10.1017/S0033291714002888. Ford T, Goodman R and Meltzer H (2003) The British Child and Adolescent Mental Health Survey 1999: the prevalence of DSM-IV disorders. Journal of the American Academy of Child and Adolescent Psychiatry 42: 1203-1211.

Fisher PW, Shaffer D, Paicentini JC, et al. (1993) Sensitivity of the Diagnostic Interview Schedule for Children, 2nd edition (DISC-2.1) for specific diagnoses of children and adolescents. Journal of the American Academy of Child and Adolescent Psychiatry 32: 666-673.

Green H, McGinnity A, Meltzer H, et al. (2005) Mental health of children and young people in Great Britain, 2004. Office for National Statistics. Houndmills, Basingstoke: Palgrave MacMillan.

Hafekost J, Lawrence D, Boterhoven de Haan K, et al. (submitted) Methodology of the second Australian Child and Adolescent Survey of Mental Health and Wellbeing. Australian and New Zealand Journal of Psychiatry (submitted)

Kessler RC, Avenevoli S, Costello J, et al. (2012) Prevalence, persistence, and sociodemographic correlates of DSM-IV disorders in the National Comorbidity 
Survey Replication Adolescent Supplement. Archives of General Psychiatry 69: 372380.

Kessler RC, Berglund P, Demler O, et al. (2005) Lifetime prevalence and age-of-onset distributions of DSM-IV disorders in the National Comorbidity Survey Replication. Archives of General Psychiatry 62: 593-602.

Kessler RC, Üstün TB, editors (2008) The WHO World Mental Health Surveys: global perspectives on the epidemiology of mental disorders. New York: Cambridge University Press.

Krol NP, De Bruyn EE, Coolen JC, van Aarle EJ (2006) From CBCL to DSM: a comparison of two methods to screen for DSM-IV diagnoses using CBCL data. Journal of Clinical Child and Adolescent Psychology 35: 127-135.

Larson RW (2002) Globalization, societal change, and new technologies: what they mean for the future of adolescence. Journal of Research on Adolescence 12: 1-30. Lawrence D, Johnson S, Hafekost J, Boterhoven de Haam K, Sawyer M, Ainley J, Zubrick SR (2015) The mental health of children and adolescents. Report on the second Australian child and adolescent survey of mental health and wellbeing. Canberra: Australian Government Department of Health.

Merikangas KR, He JP, Brody D, et al. (2010) Prevalence and treatment of mental disorders among US children in the 2001-2004 NHANES. Pediatrics 125: 75-81. 
Merikangas KR, Nakamura EF, and Kessler RC (2009) Epidemiology of mental disorders in children and adolescents. Dialogues in Clinical Neuroscience 11: 7-20.

Patel V, Flisher AJ, Hetrick S, et al. (2007) Mental health of young people: a global public-health challenge. Lancet 369: 1302-1313.

Patton GC, Coffey C, Romaniuk H, et al. (2014) The prognosis of common mental disorders in adolescents: a 14-year prospective cohort study. Lancet 383: 14041411.

Polanczyk G, Willcutt EG, Salum GA, et al. (2014) ADHD prevalence estimates across three decades: an updated systematic review and meta-regression analysis. International Journal of Epidemiology 43: 434-442.

Polanczyk GV, Salum GA, Sugaya LS, et al. (2015) Annual research review: A metaanalysis of the worldwide prevalence of mental disorders in children and adolescents. Journal of Child Psychology and Psychiatry 56: 345-365

SAS Institute Inc (2014) SAS/STAT Software, Version 9.4. Cary, NC: SAS Institute Inc. Sawyer MG, Arney PA, Baghurst PA, et al. (2001) The mental health of young people in Australia: key findings from the Child and Adolescent Component of the National Survey of Mental Health and Well-being. Australian and New Zealand Journal of Psychiatry 35: 806-814. 
Sawyer MG, Kosky RJ, Graetz BW, et al. (2000) The National Survey of Mental Health and Wellbeing: the child and adolescent component. Australian and New Zealand Journal of Psychiatry. 34: 214-220.

Shaffer D, Fisher P, Lucas C, et al. (2000) NIMH Diagnostic Interview Schedule for Children, Version IV (NIMH DISC-IV): description, differences from previous versions and reliability of some common diagnoses. Journal of the American Academy of Child and Adolescent Psychiatry 39: 28-38.

Slade T, Johnston A, Oakley Browne MA, et al. (2009) 2007 National Survey of Mental Health and Wellbeing: methods and key findings. Australian and New Zealand Journal of Psychiatry 43: 594-605.

U.S. Department of Health and Human Services (1999) Mental health: A report of the Surgeon General. Rockville MD: U.S. Department of Health and Human Services, Substance Abuse and Mental Health Services Administration, Center for Mental Health Services, National Institutes of Health, National Institute of Mental Health. West P and Sweeting H (2003) Fifteen, female and stressed: changing patterns of psychological distress over time. Journal of Child Psychology and Psychiatry 44: 399-411.

Wolter KM (2007) Introduction to variance estimation, Second Edition. New York: Springer. 
Zubrick SR, Hafekost J, Johnson S, et al. (submitted a) Self harm: prevalence estimates from the second Australian Child and Adolescent Survey of Mental Health and Wellbeing. Australian and New Zealand Journal of Psychiatry (submitted)

Zubrick SR, Hafekost J, Johnson S, et al. (submitted b) Suicidal behaviours: prevalence estimates from the second Australian Child and Adolescent Survey of Mental Health and Wellbeing. Australian and New Zealand Journal of Psychiatry (submitted)

Zubrick SR, Lawrence D, Johnson S, et al. (2015c) Measuring severity of mental disorders with the Young Minds Matter parent/carer-reported impact items. Technical Report. Perth: Telethon Kids Institute, The University of Western Australia. 
Table 1: 30-day and 12-month prevalence of mental disorders in 4-17 year-olds

\begin{tabular}{|c|c|c|c|c|c|c|c|c|c|c|}
\hline \multirow[b]{2}{*}{ Disorder } & \multicolumn{3}{|c|}{ 30-day prevalence } & \multicolumn{3}{|c|}{ 12-month prevalence } & \multicolumn{2}{|c|}{ Prevalence ratio } & \multicolumn{2}{|c|}{$\begin{array}{l}\text { 12-month prevalence } \\
\text { principal condition }\end{array}$} \\
\hline & EPC & $\%$ & $95 \% \mathrm{Cl}$ & EPC & $\%$ & $95 \% \mathrm{Cl}$ & $30-d / 12-m$ & $95 \% \mathrm{Cl}$ & $\%$ & $95 \% \mathrm{Cl}$ \\
\hline Any anxiety disorder- & 135,000 & 3.4 & $(2.8-3.9)$ & 278,000 & 6.9 & $(6.2-7.6)$ & 49 & $(43-54)$ & 5.4 & $(4.8-6.0)$ \\
\hline Social phobia & 45,200 & 1.1 & $(0.9-1.4)$ & 93,500 & 2.3 & $(1.9-2.7)$ & 48 & $(40-56)$ & 1.3 & $(1.0-1.6)$ \\
\hline Separation anxiety disorder & 69,400 & 1.7 & $(1.3-2.1)$ & 171,000 & 4.3 & $(3.7-4.8)$ & 41 & $(34-47)$ & 2.9 & $(2.4-3.3)$ \\
\hline Generalised anxiety disorder & 42,800 & 1.1 & $(0.8-1.4)$ & 87,400 & 2.2 & $(1.8-2.6)$ & 49 & $(40-58)$ & 1.0 & $(0.8-1.3)$ \\
\hline Obsessive-compulsive disorder & 20,900 & 0.5 & $(0.3-0.7)$ & 32,600 & 0.8 & $(0.6-1.1)$ & 64 & $(50-78)$ & 0.2 & $(0.1-0.3)$ \\
\hline Major depressive disorder & 26,600 & 0.7 & $(0.4-0.9)$ & 112,000 & 2.8 & $(2.4-3.2)$ & 24 & $(17-31)$ & 2.0 & $(1.6-2.3)$ \\
\hline $\begin{array}{l}\text { Attention-deficit/hyperactivity } \\
\text { disorder }\end{array}$ & 238,000 & 5.9 & $(5.2-6.7)$ & 298,000 & 7.4 & $(6.6-8.2)$ & 80 & $(76-84)$ & 5.5 & $(4.9-6.2)$ \\
\hline Conduct disorder & 83,300 & 2.1 & $(1.6-2.5)$ & 83,600 & 2.1 & $(1.6-2.5)$ & 100 & $(99-100)$ & 1.1 & $(0.8-1.4)$ \\
\hline Any disorder & 375,000 & 9.3 & $(8.5-10.2)$ & 560,000 & 13.9 & $(12.9-15.0)$ & 67 & $(63-70)$ & 13.9 & $(12.9-15.0)$ \\
\hline
\end{tabular}

$\%=$ weighted percentage; $\mathrm{Cl}$, confidence interval; EPC, estimated population count. EPCs are rounded to 3 significant digits 
Table 2: 12-month prevalence of mental disorders by sex and age group

\begin{tabular}{|c|c|c|c|c|c|c|c|c|}
\hline \multirow[b]{3}{*}{ Disorder } & \multicolumn{4}{|c|}{ Males } & \multicolumn{4}{|c|}{ Females } \\
\hline & \multicolumn{2}{|c|}{$4-11$ years } & \multicolumn{2}{|c|}{$12-17$ years } & \multicolumn{2}{|c|}{$4-11$ years } & \multicolumn{2}{|c|}{$12-17$ years } \\
\hline & $\%$ & $95 \% \mathrm{Cl}$ & $\%$ & $95 \% \mathrm{Cl}$ & $\%$ & $95 \% \mathrm{Cl}$ & $\%$ & $95 \% \mathrm{Cl}$ \\
\hline Any anxiety disorder- & 7.6 & $(6.2-8.9)$ & 6.3 & $(4.9-7.7)$ & 6.1 & $(4.9-7.4)$ & 7.7 & $(6.2-9.2)$ \\
\hline Social phobia & 1.8 & $(1.1-2.5)$ & 3.3 & $(2.3-4.3)$ & 1.3 & $(0.7-1.9)$ & 3.4 & $(2.5-4.4)$ \\
\hline $\begin{array}{l}\text { Separation anxiety } \\
\text { disorder }\end{array}$ & 4.9 & $(3.9-6.0)$ & 3.8 & $(2.6-5.0)$ & 4.8 & $(3.7-5.9)$ & 3.1 & $(2.1-4.0)$ \\
\hline $\begin{array}{l}\text { Generalised anxiety } \\
\text { disorder }\end{array}$ & 1.8 & $(1.1-2.5)$ & 2.3 & $(1.5-3.2)$ & 1.5 & $(0.9-2.2)$ & 3.4 & $(2.5-4.4)$ \\
\hline $\begin{array}{l}\text { Obsessive- } \\
\text { compulsive disorder }\end{array}$ & 1.3 & $(0.7-1.8)$ & 0.9 & $(0.3-1.5)$ & 0.3 & $(0.1-0.6)$ & 0.7 & $(0.3-1.2)$ \\
\hline $\begin{array}{l}\text { Major depressive } \\
\text { disorder }\end{array}$ & 1.1 & $(0.6-1.6)$ & 4.3 & $(3.2-5.5)$ & 1.2 & $(0.7-1.8)$ & 5.8 & $(4.5-7.1)$ \\
\hline $\begin{array}{l}\text { Attention- } \\
\text { deficit/hyperactivity } \\
\text { disorder }\end{array}$ & 10.9 & $(9.3-12.6)$ & 9.8 & $(8.0-11.6)$ & 5.4 & $(4.2-6.6)$ & 2.7 & $(1.7-3.6)$ \\
\hline Conduct disorder & 2.5 & $(1.6-3.3)$ & 2.6 & $(1.6-3.6)$ & 1.6 & $(0.9-2.3)$ & 1.6 & $(0.8-2.4)$ \\
\hline Any disorder & 16.5 & $(14.5-18.5)$ & 15.9 & $(13.8-18.1)$ & 10.6 & $(9.0-12.2)$ & 12.8 & $10.8-14.7)$ \\
\hline
\end{tabular}


Table 3: 12-month prevalence of major depressive disorder by sex, age group and informant

\begin{tabular}{|c|c|c|c|c|c|c|c|}
\hline & & \multicolumn{6}{|c|}{ Informant } \\
\hline & & \multicolumn{2}{|c|}{ Parent or carer } & \multicolumn{2}{|c|}{ Youth } & \multicolumn{2}{|c|}{$\begin{array}{c}\text { Either parent or carer or } \\
\text { youth }\end{array}$} \\
\hline & & $\%$ & $95 \% \mathrm{Cl}$ & $\%$ & $95 \% \mathrm{Cl}$ & $\%$ & $95 \% \mathrm{Cl}$ \\
\hline \multirow[t]{2}{*}{ Males } & $11-15$ years & 3.1 & $(1.8-4.3)$ & 3.1 & $(1.9-4.2)$ & 5.4 & $(3.9-7.0)$ \\
\hline & $16-17$ years & 5.4 & $(3.7-7.1)$ & 8.2 & $(6.2-10.1)$ & 11.4 & $(9.2-13.6)$ \\
\hline \multirow[t]{2}{*}{ Females } & $11-15$ years & 3.6 & $(2.1-5.0)$ & 7.2 & $(5.3-9.2)$ & 9.5 & $(7.3-11.7)$ \\
\hline & $16-17$ years & 10.6 & $(8.2-12.9)$ & 19.6 & $(16.6-22.5)$ & 24.3 & $(21.1-27.5)$ \\
\hline
\end{tabular}

$\%=$ weighted percentage, $\mathrm{Cl}=$ confidence interval; 
Table 4: 12-month prevalence of mental disorders in 4-17 year-olds by sociodemographic characteristics

\begin{tabular}{|c|c|c|c|c|c|c|c|}
\hline Characteristic & $\mathrm{n}$ & $\%$ & $95 \% \mathrm{Cl}$ & $\begin{array}{l}\text { Uni- } \\
\text { variate } \\
\text { odds ratio } \\
\text { (a) }\end{array}$ & $95 \% \mathrm{Cl}$ & $\begin{array}{l}\text { Multi- } \\
\text { variate } \\
\text { odds } \\
\text { ratio (b) }\end{array}$ & $95 \% \mathrm{Cl}$ \\
\hline \multicolumn{8}{|l|}{ Family type- } \\
\hline Original family & 4331 & 10.4 & $(9.4-11.5)$ & 1 & (ref) & 1 & (ref) \\
\hline Step family & 283 & 18.3 & $(12.9-23.7)$ & 1.9 & $(1.3-2.9)$ & 1.4 & $(1.0-2.1)$ \\
\hline Blended family & 392 & 20.2 & $(15.9-24.4)$ & 2.2 & $(1.7-2.9)$ & 1.6 & $(1.2-2.1)$ \\
\hline Sole parent or carer family & 1250 & 22.4 & $(19.7-25.1)$ & 2.5 & $(2.1-3.0)$ & 1.5 & $(1.2-2.0)$ \\
\hline Other family & 54 & 23.7 & $(13.3-34.0)$ & 2.7 & $(1.5-4.9)$ & 1.7 & $(0.9-3.5)$ \\
\hline \multicolumn{8}{|l|}{ Carer country of birth (d)- } \\
\hline Both carers born in Australia & 2977 & 14.3 & $(12.8-15.8)$ & 1 & (ref) & 1 & (ref) \\
\hline $\begin{array}{l}\text { One carer born in Australia, } \\
\text { One carer born overseas }\end{array}$ & 929 & 12.9 & $(10.6-15.1)$ & 0.9 & $(0.7-1.1)$ & 0.9 & $(0.7-1.2)$ \\
\hline Both carers born overseas & 1188 & 5.1 & $(3.7-6.5)$ & 0.3 & $(0.2-0.4)$ & 0.4 & $(0.3-0.6)$ \\
\hline Sole carer born in Australia & 956 & 24.6 & $(21.6-27.7)$ & 2.0 & $(1.6-2.4)$ & 1 & (ref) \\
\hline Sole carer born overseas & 260 & 13.4 & $(8.8-18.0)$ & 0.9 & $(0.6-1.4)$ & 0.6 & $(0.4-0.9)$ \\
\hline \multicolumn{8}{|l|}{ Carer main language spoken $(\mathrm{e})-$} \\
\hline Both carers English & 4437 & 13.1 & $(12.0-14.3)$ & 1 & (ref) & 1 & (ref) \\
\hline $\begin{array}{l}\text { One carer English, one carer } \\
\text { other language }\end{array}$ & 551 & 8.5 & $(3.0-14.1)$ & 0.6 & $(0.3-1.3)$ & 0.6 & $(0.2-1.6)$ \\
\hline Both carers other language & 570 & 3.1 & $(1.4-4.7)$ & 0.2 & $(0.1-0.4)$ & 0.4 & $(0.2-0.8)$ \\
\hline Sole carer English & 1157 & 23.1 & $(20.3-25.9)$ & 2.0 & $(1.7-2.4)$ & 1 & (ref) \\
\hline Sole carer other language & 58 & 7.5 & $(0.0-15.2)$ & 0.5 & $(0.2-1.6)$ & 0.3 & $(0.1-0.9)$ \\
\hline \multicolumn{8}{|l|}{ Household income- } \\
\hline Less than $\$ 52,000$ per year & 1479 & 20.5 & $(18.1-22.9)$ & 2.2 & $(1.7-2.7)$ & (c) & \\
\hline$\$ 52,000-\$ 129,999$ per year & 2833 & 12.3 & $(11.0-13.7)$ & 1.2 & $(1.0-1.5)$ & & \\
\hline$\$ 130,000$ or more per year & 1686 & 10.5 & $(8.8-12.2)$ & 1 & (ref) & & \\
\hline Not stated & 312 & 9.6 & $(6.4-12.9)$ & 0.9 & $(0.6-1.4)$ & & \\
\hline \multicolumn{8}{|l|}{$\begin{array}{l}\text { Index of relative socio-economic } \\
\text { disadvantage- }\end{array}$} \\
\hline $\begin{array}{l}\text { Lowest quintile (most } \\
\text { disadvantaged) }\end{array}$ & 1055 & 20.7 & $(17.6-23.8)$ & 2.1 & $(1.6-2.7)$ & (c) & \\
\hline Second quintile & 1180 & 14.4 & $(12.1-16.7)$ & 1.4 & $(1.1-1.8)$ & & \\
\hline Third quintile & 1188 & 13.3 & $(11.0-15.5)$ & 1.3 & $(10-1.6)$ & & \\
\hline Fourth quintile & 1436 & 11.7 & $(9.7-13.7)$ & 1.1 & $(0.8-1.4)$ & & \\
\hline $\begin{array}{l}\text { Highest quintile (most } \\
\text { advantaged) }\end{array}$ & 1451 & 10.9 & $(9.3-12.6)$ & 1 & (ref) & & \\
\hline \multicolumn{8}{|l|}{ Parent or carer education (f) - } \\
\hline Bachelor degree or higher & 2667 & 10.6 & $(9.3-12.0)$ & 1 & (ref) & (c) & \\
\hline Diploma or certificate III/IV & 2414 & 15.8 & $(14.2-17.4)$ & 1.6 & $(1.3-1.9)$ & & \\
\hline Year 11 or 12 & 756 & 15.4 & $(12.5-18.3)$ & 1.5 & $(1.2-2.0)$ & & \\
\hline Year 10 or below & 473 & 19.7 & $(15.6-23.8)$ & 2.0 & $(1.5-2.7)$ & & \\
\hline
\end{tabular}




\begin{tabular}{|c|c|c|c|c|c|c|c|}
\hline Characteristic & $\mathrm{n}$ & $\%$ & $95 \% \mathrm{Cl}$ & $\begin{array}{c}\text { Uni- } \\
\text { variate } \\
\text { odds ratio } \\
\text { (a) }\end{array}$ & $95 \% \mathrm{Cl}$ & $\begin{array}{l}\text { Multi- } \\
\text { variate } \\
\text { odds } \\
\text { ratio (b) }\end{array}$ & $95 \% \mathrm{Cl}$ \\
\hline \multicolumn{8}{|l|}{ Parent or carer employment (g)- } \\
\hline Both carers employed & 3422 & 10.8 & $(9.6-12.0)$ & 1 & (ref) & 1 & (ref) \\
\hline $\begin{array}{l}\text { One carer employed, one } \\
\text { carer not in employment }\end{array}$ & 1459 & 12.9 & $(11.0-14.8)$ & 1.2 & $(1.0-1.5)$ & 1.3 & $(1.0-1.6)$ \\
\hline $\begin{array}{l}\text { Both carers not in } \\
\text { employment }\end{array}$ & 209 & 21.3 & $(14.8-27.8)$ & 2.2 & $(1.5-3.3)$ & 1.9 & $(1.3-2.9)$ \\
\hline Sole carer employed & 743 & 17.0 & $(14.1-19.8)$ & 1.7 & $(1.3-2.1)$ & 1 & (ref) \\
\hline Sole carer not in employment & 477 & 29.6 & $(25.1-34.1)$ & 3.5 & $(2.7-4.4)$ & 1.8 & $(1.3-2.4)$ \\
\hline \multicolumn{8}{|l|}{ Housing tenure- } \\
\hline Owned outright & 777 & 10.5 & $(8.0-13.0)$ & 1 & (ref) & 1 & (ref) \\
\hline Owned with a mortgage & 3488 & 11.2 & $(10.0-12.5)$ & 1.1 & $(0.8-1.5)$ & 1.2 & $(0.9-1.7)$ \\
\hline Rented - public housing & 268 & 29.2 & $(23.6-34.8)$ & 3.6 & $(2.5-5.2)$ & 2.2 & $(1.5-3.2)$ \\
\hline Rented - other & 1677 & 17.7 & $(15.7-19.8)$ & 1.9 & $(1.4-2.6)$ & 1.8 & $(1.3-2.5)$ \\
\hline Other & 100 & 18.2 & $(9.3-27.1)$ & 2.0 & $(1.0-3.9)$ & 1.8 & $(0.9-3.6)$ \\
\hline \multicolumn{8}{|l|}{ Remoteness area- } \\
\hline Major Cities of Australia & 4134 & 12.9 & $(11.7-14.1)$ & 1 & (ref) & (c) & \\
\hline Inner Regional Australia & 1554 & 14.8 & $(12.4-17.1)$ & 1.1 & $(0.9-1.4)$ & & \\
\hline Outer Regional Australia & 516 & 19.0 & $(15.1-22.9)$ & 1.6 & $(1.2-2.1)$ & & \\
\hline $\begin{array}{l}\text { Remote Australia or Very } \\
\text { Remote Australia }\end{array}$ & 106 & 14.0 & $(7.8-20.3)$ & 1.1 & $(0.7-1.9)$ & & \\
\hline
\end{tabular}

$\mathrm{n}=$ unweighted number of respondents; \% = weighted percentage; $\mathrm{Cl}=$ confidence interval;

(a) odds ratio from a separate logistic regression model for each characteristic, only adjusting for age, sex and that characteristic;

(b) odds ratio from overall multivariate logistic regression model including all characteristics in model and age and sex;

(c) characteristic not significantly associated with prevalence of disorder in final multivariate model;

(d) as two parent/carer or one parent/carer family structure is already accounted for in family type, in the multivariate model odds are calculated relative to both parents or carers born in Australia for two parent or carer families, and relative to sole parent or carer born in Australia for one parent or carer families;

(e) as two parent/carer or one parent/carer family structure is already accounted for in family type, in the multivariate model odds are calculated relative to both parents or carers having English as their main language for two parent or carer families, and relative to sole parent or carer having English as their main language for one parent or carer families;

(f) highest level of educational attainment achieved by either parent or carer;

(g) as two parent/carer or one parent/carer family structure is already accounted for in family type, in the multivariate model odds are calculated relative to both parents or carers in employment for two parent or carer families, and relative to sole parent or carer in employment for one parent or carer families. 
Table 5: 12-month prevalence of mental disorders by severity

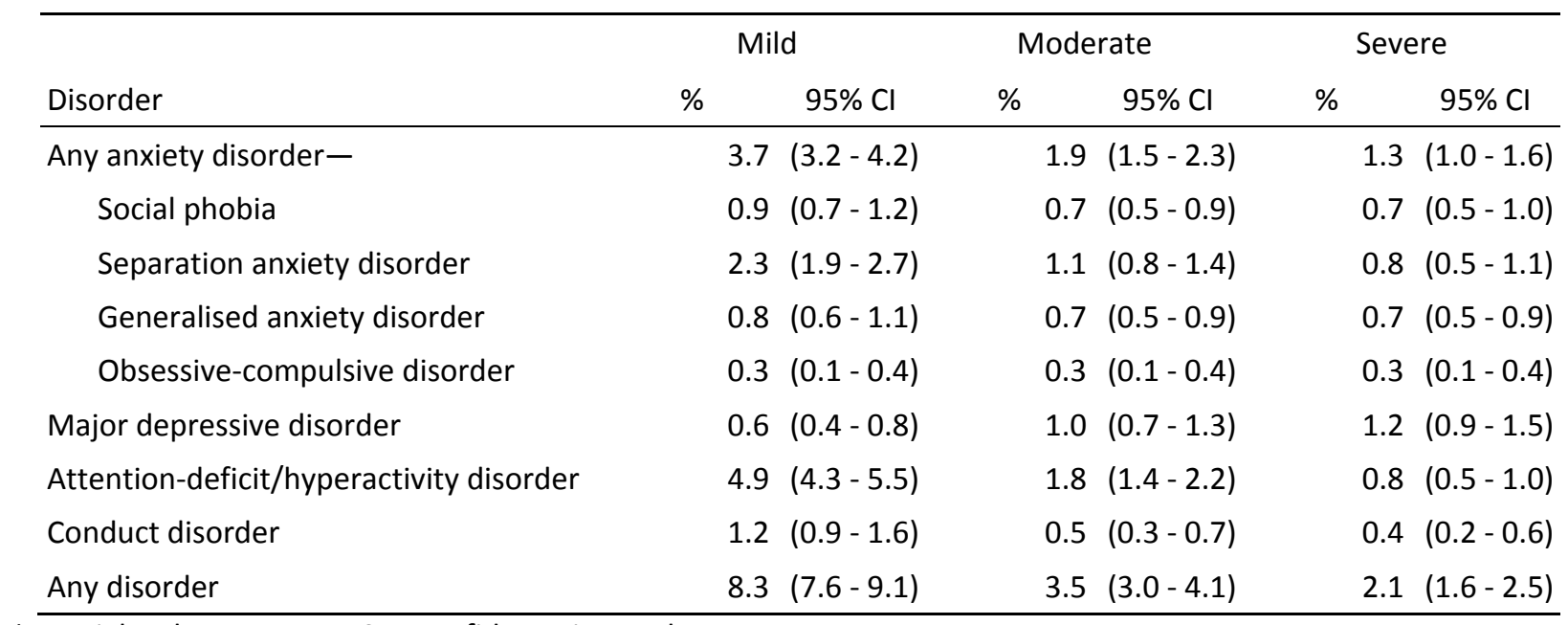

$\%$ = weighted percentage; $\mathrm{Cl}$ = confidence interval; 
Table 6: Days off school in past 12 months due to symptoms of mental disorders by age group

\begin{tabular}{|c|c|c|c|c|c|c|c|c|c|}
\hline \multirow[b]{2}{*}{ Disorder } & \multicolumn{3}{|c|}{$4-11$ years } & \multicolumn{3}{|c|}{$12-17$ years } & \multicolumn{3}{|c|}{$4-17$ years } \\
\hline & Mean & Median & IQR & Mean & Median & IQR & Mean & Median & IQR \\
\hline Any anxiety disorder- & 6.2 & 1 & $(0-6)$ & 20.4 & & $(0-21)$ & 12.1 & & $(0-13)$ \\
\hline Social phobia & 7.9 & 4 & $(0-7)$ & 20.3 & 10 & $(0-22)$ & 15.2 & & $(0-16)$ \\
\hline Separation anxiety disorder & 6.3 & 1 & $(0-7)$ & 29.5 & 10 & $(2-35)$ & 13.9 & & $(0-13)$ \\
\hline Generalised anxiety disorder & 10.4 & 3 & $(0-12)$ & 22.5 & 12 & $(1-26)$ & 16.6 & 5 & $(0-20)$ \\
\hline Obsessive-compulsive disorder & 7.2 & 0 & $(0-11)$ & 22.5 & 8 & $(0-18)$ & 14.0 & 3 & $(0-15)$ \\
\hline Major depressive disorder & 13.7 & 8 & $(0-20)$ & 22.6 & 10 & $(0-28)$ & 20.2 & 9 & $(0-28)$ \\
\hline $\begin{array}{l}\text { Attention-deficit/hyperactivity } \\
\text { disorder }\end{array}$ & 3.6 & 0 & $(0-1)$ & 9.0 & 0 & $(0-10)$ & 5.5 & 0 & $(0-4)$ \\
\hline Conduct disorder & 2.0 & 0 & $(0-0)$ & 17.3 & 4 & $(0-26)$ & 8.5 & 0 & $(0-6)$ \\
\hline
\end{tabular}

